\title{
ANOMALOUS RIGHT SUBCLAVIAN ARTERY
}

\author{
BY \\ J. N. PATTINSON \\ From the Diagnostic X-Ray Department, Middlesex Hospital \\ Received December 15, 1952
}

\begin{abstract}
Abnormalities in the course of the arteries arising from the aortic arch are not uncommon. These vessels may arise from as many as five or from as few as two main trunks and their order of origin may also vary. An aberrant right subclavian artery arising as the last vessel from the aortic arch is a relatively frequent form of these congenital anomalies.

Of the early descriptions of this condition, Bayford's in 1794, is perhaps the best known, although Hunauld has been credited with the first report in 1735. Holzapfel (1899) found reports of 193 human specimens showing the anomaly and added 5 of his own: he gave an incidence of 0.6 per cent in the post-mortem material examined in this series. Cairney (1925) described two anatomical specimens and found reports of an additional 19 in a total of 2494 necropsies, an incidence of 0.8 per
\end{abstract} cent.

In 1936 the anomaly was first recognized during life by Kommerell during the course of a barium meal examination. Other single cases were diagnosed radiologically by Zdansky (1939), Gunsel (1940), Copleman (1945), and Stauffer and Pote (1946). Two examples were described by Dahm (1940) and two by Ravelli (1950). Anatomical confirmation was obtained in Zdansky's patient only, who was examined post mortem.

During the last five years an increasing number of cases have been recorded. Brean and Neuhauser described 15 examples in 1947. Felson et al. (1950) describe their findings in nine patients without symptoms, in all of whom the radiological diagnosis was made by study of the barium filled osophagus. Apley (1949) by angiocardiography in a child demonstrated the course of the vessel between the œsophagus and trachea. Kreutzer et al. (1950) showed it in the same position in a child with Fallot's tetralogy: their observations were confirmed at necropsy. Raphael et al. (1952) passed a radio-opaque catheter from the right brachial artery through the right subclavian artery into the aorta to confirm that the impression on the posterior wall of the cesophagus was due to the anomalous course of the right subclavian artery.

Bahnson and Blalock (1950) encountered 18 instances of aberrant right subclavian artery and 18 cases of aberrant left subclavian artery in 841 patients operated on for suspected congenital pulmonary stenosis. Gross and Neuhauser (1951) found 10 examples in a series of 40 babies operated on for the relief of tracheal or æsophageal obstruction.

\section{ANATOMY AND EMBRYOLOGY}

The anomalous right subclavian artery may arise from the medial or upper aspect of a normal left-sided aortic arch or less commonly at the junction of the arch and descending aorta. Its origin is on the left of the mid line and caudal to the origin of the left subclavian artery. Typically the vessel courses upwards and to the right, posterior to the œsophagus and emerges from the thorax over the first right rib (Fig. 1).

Frequently the artery is dilated at its origin or arises from an aortic diverticulum. Holzapfel described this in 33 out of 55 cases in which the size of the vessel was recorded. He also found that although the artery was usually retro-œsophageal, it passed between the œsophagus and trachea in 15 per cent and anterior to the trachea in 5 per cent of his series. 


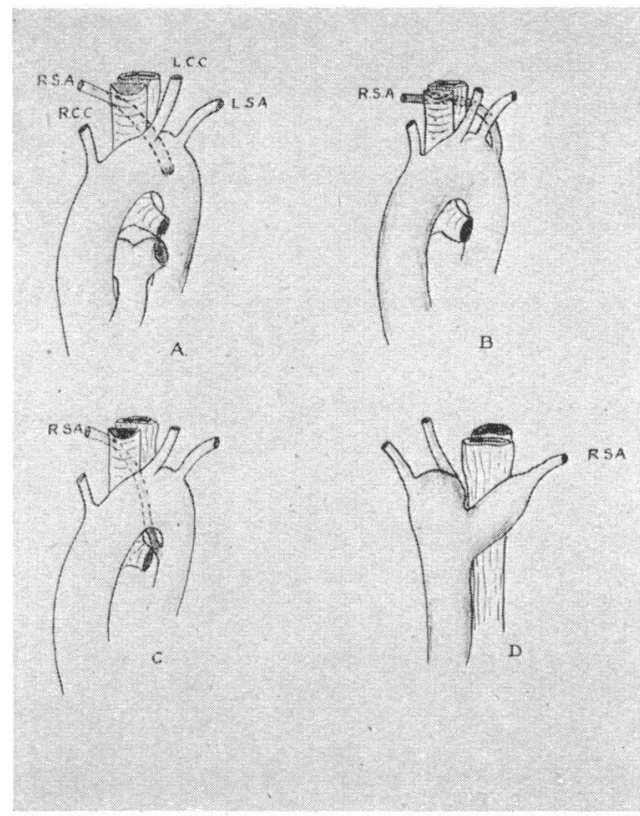

FIG. 1.-The anterior views (A), (B), and (C) show variations in the origin of the anomalous right subclavian artery. The posterior view (D) demonstrates the vessel that is dilated at its origin.

There is also a very rare type of anomalous right subclavian artery, the only known example being a post-mortem specimen described by Edwards in 1948. The aorta ascended normally to the left of the cesophagus and then turned posterior to it to reach the right side of the mid line. The descending aorta lay to the right of the spine and at its junction with the arch an aortic diverticulum was present. The right subclavian artery originated from this diverticulum as the fourth branch of the arch and passed upwards and to the right to reach the first rib.

Embryology. The transformation of the embryonic aortic arch system has been described in the classical work of Congdon (1922). Cairney (1925) has dealt with the developmental aspects of the anomalous right subclavian artery in detail. The generally accepted view is that the caudal segment of the right dorsal aorta fails to become absorbed and is incorporated in the origin of the right subclavian artery. It may remain dilated and so form an aortic diverticulum. The right fourth aortic arch and cephalic portion of the right dorsal aorta which normally give origin to the right subclavian artery cease to function and disappear completely. As a result the right subclavian artery arises from the aortic arch distal to the origin of the left subclavian artery and in the majority of instances runs a retro-oesophageal course. The first vessel arising from the aortic arch is usually the right common carotid artery, followed by the left common carotid and left subclavian arteries, the right subclavian artery being the last branch of the aortic arch. Holzapfel gives nine other variations in the origin of these vessels.

It is difficult to explain how the aberrant right subclavian may come to lie anterior to the trachea or between it and the œsophagus. Holzapfel has suggested that of the many vascular roots which are available in the embryo, an unusual one is preserved. Thus in the very early stage of development some anastomotic channel lying anterior to the foregut may have reached a high state of development.

\section{Radiological Findings}

The diagnosis can be made on the characteristic appearances of the barium filled œsophagus as described by Neuhauser (1946) and by others. In the postero-anterior view the artery produces an oblique indentation on the posterior œsophageal wall (Fig. 2 and 3). This starts on the left side 

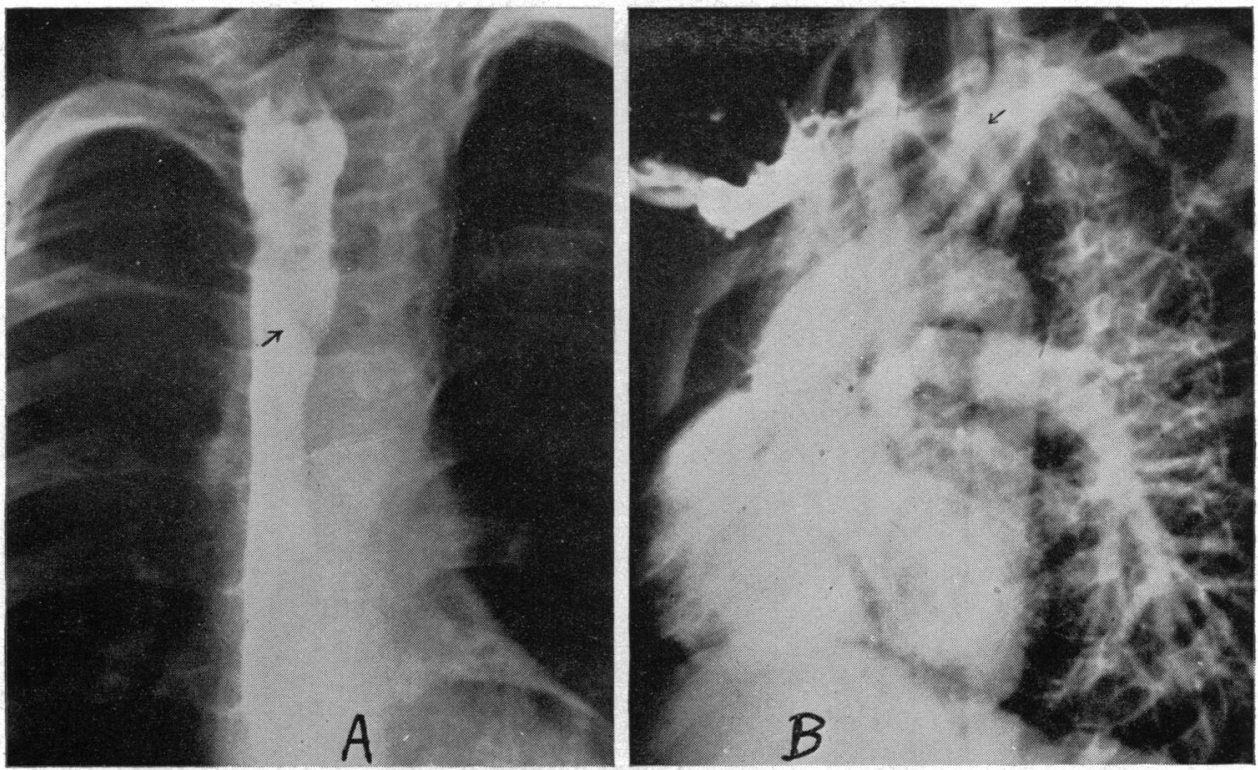

Fig. 2.-A.P. position. Case 1, aged 4 years. Fallot's tetralogy. (A) A faint oblique impression can be seen on the posterior oesophageal wall passing upwards and to the right from the level of the aortic arch. (B) Angiocardiogram at 2 sec. in the L.A.O. position. The right subclavian artery arises posterior to the left subclavian artery and passes upwards, forwards and to the right.
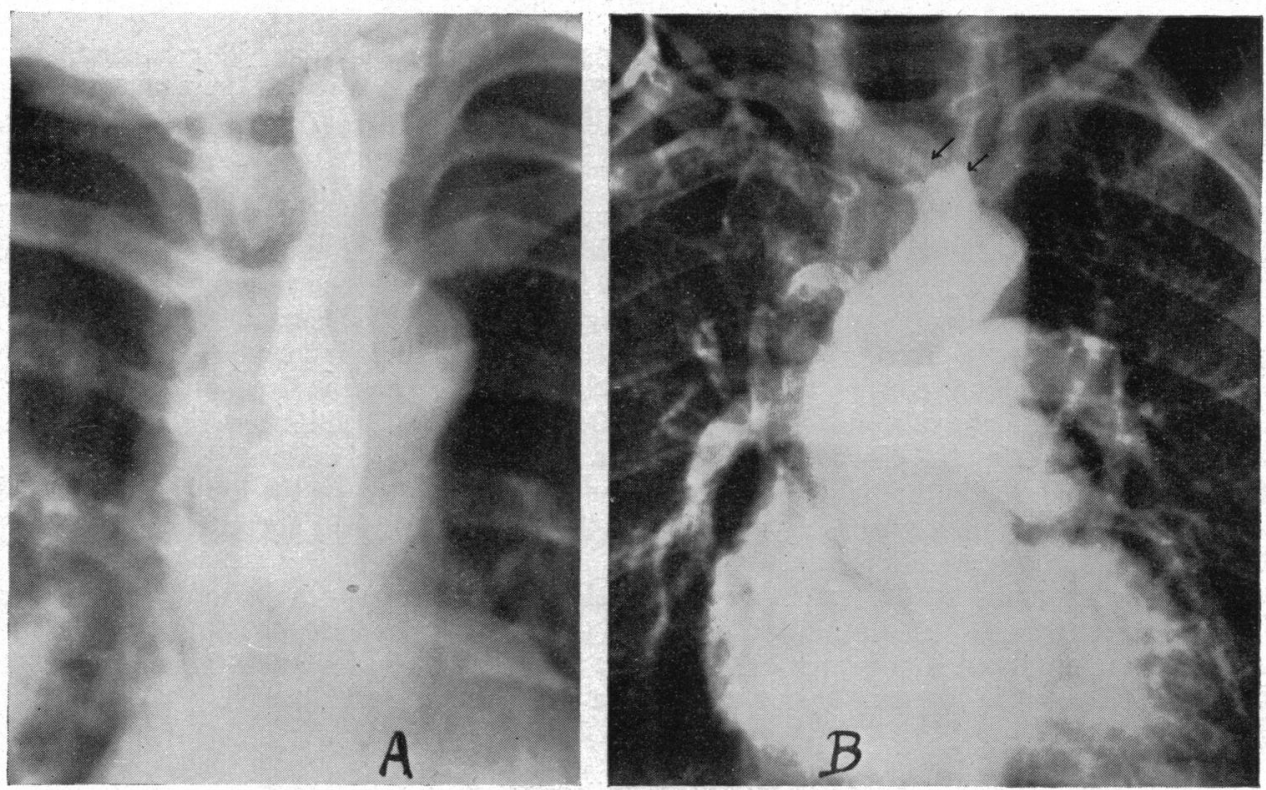

Fig. 3.-A.P. position. Case 2, aged 4 years. Fallot's tetralogy. (A) Broad oblique indentation present on the osophagus running up and to the right from the level of the aortic arch. (B) Angiocardiogram at $2 \frac{1}{4} \mathrm{sec}$. in A.P. position. The proximal part of the right subclavian artery is visible on the left side of the right common carotid artery. 

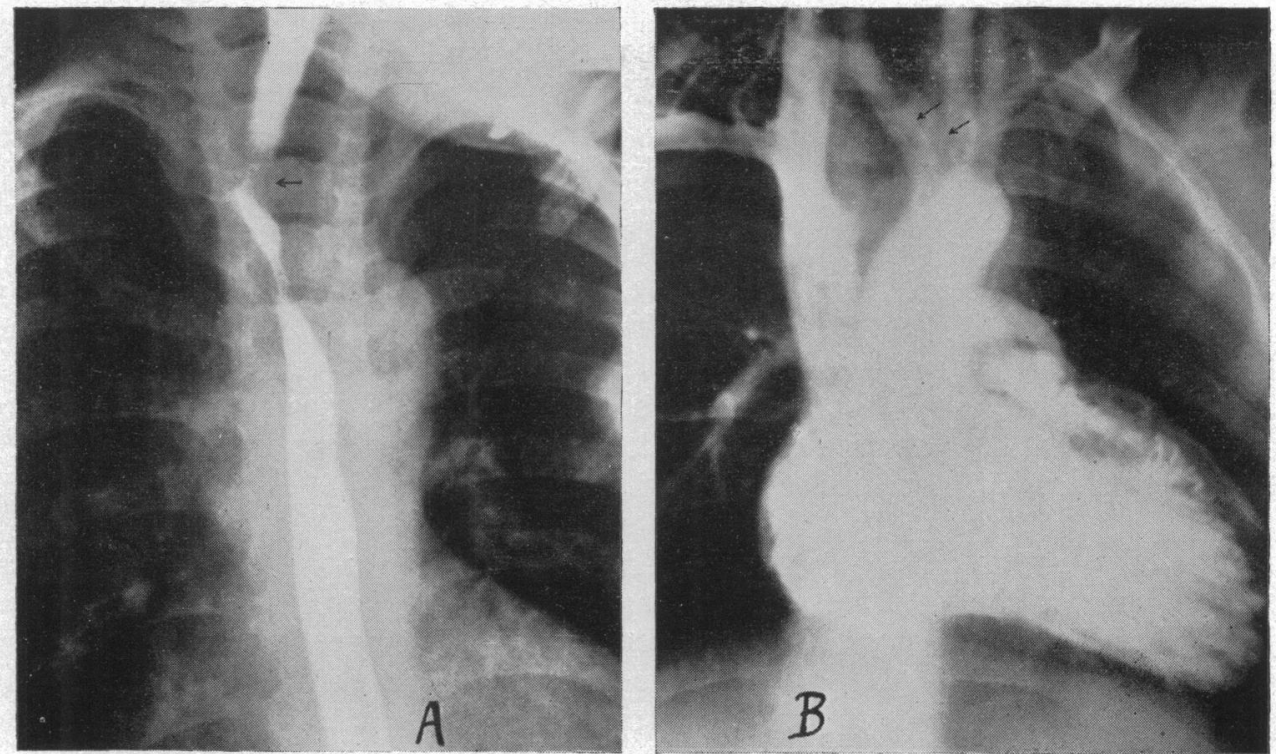

FIG. 4.-A.P. position. Case 3, aged $3 \frac{1}{2}$ years. Fallot's tetralogy. (A) Film shows an oblique impression on the posterior wall of the osophagus a little above the level of the aortic arch. The oesophagus is slightly displaced to the right. (B) Angiocardiogram at $2 \mathrm{sec}$. in A.P. position. The proximal part of the right subclavian artery can be seen on the left side of the right common carotid artery.
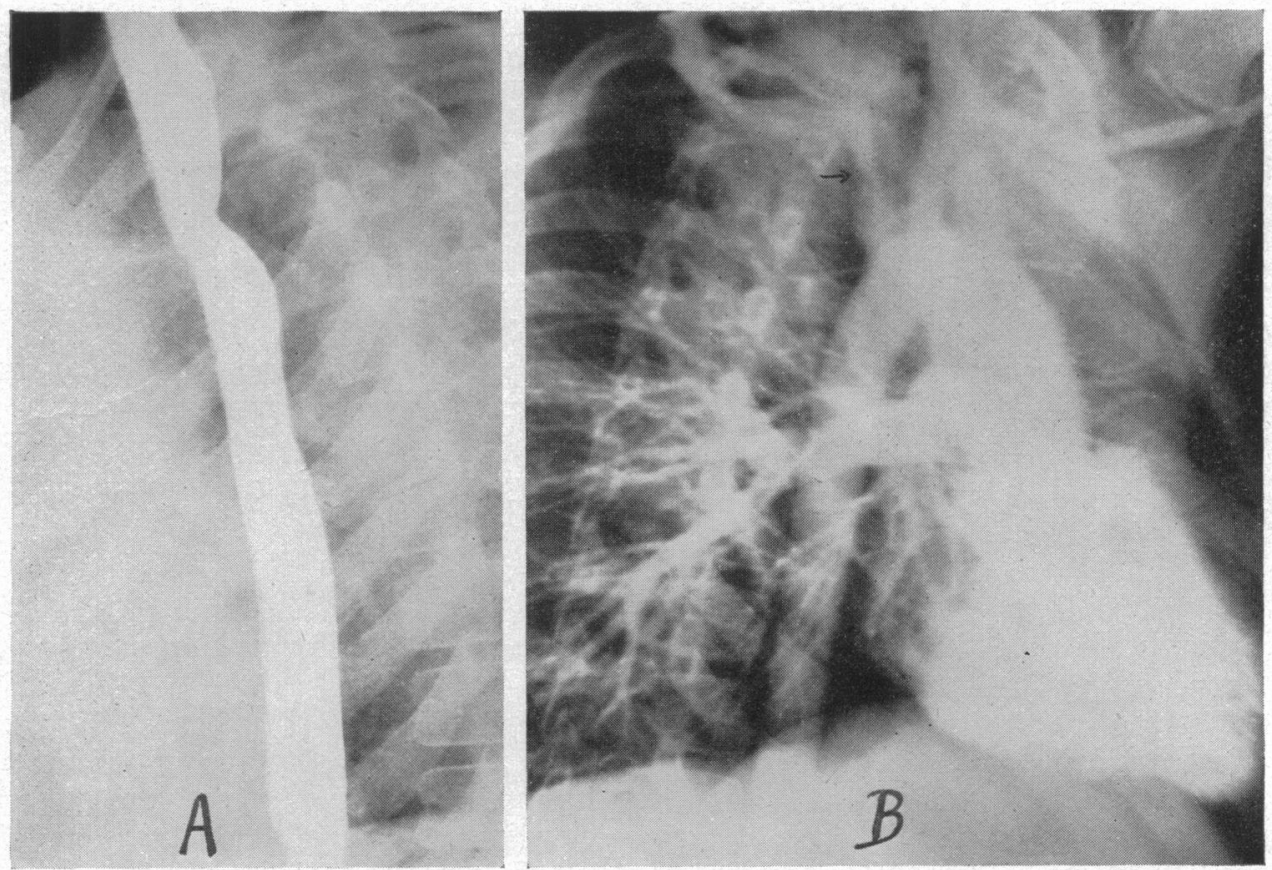

FIG. 5.-L.A.O. position. Case 4, aged 7 years. Fallot's tetralogy. (A) An angular impression is shown on the posterior wall of the oesophagus in the oblique position. (B) Angiocardiogram at $2 \mathrm{sec}$. in R.A.O. position. The right subclavian artery arises at the junction of the arch and descending aorta, runs upwards and to the right to the first rib. 
of the œsophagus just above the aortic arch impression and passes upwards and to the right. Commonly the defect is about $5 \mathrm{~mm}$. wide, but may be $15 \mathrm{~mm}$. or more if the artery is dilated at its root or it arises from an aortic diverticulum. The indentation may be deepest towards the left side of the œesophagus and fade out on the right side or there may be an impression on the right side of the œsophagus as well (Fig. 3 and 4). When a large bolus of barium is swallowed the indentation may be completely obscured in this position.

The course of this artery is best seen in the lateral view (Fig. 6B). There is a semicircular impression on the posterior csophageal wall at about the level of the aortic arch with narrowing of the œsophageal lumen. If the artery runs fairly obliquely the impression will be more angular. The size of the defect will of course vary with the size of the retro-œsophageal artery. The impression is usually well seen in the L.A.O. position (Fig. 5A) and its oblique course can be appreciated. In the R.A.O. position the defect may be less obvious although in some cases it is clearly shown. Transmitted pulsation on the posterior cesophageal wall at the level of the artery can be detected in some cases.

These typical appearances may be modified. If the aortic arch is unusually high the artery will produce an almost horizontal impression. If it arises from a low arch it will pass almost vertically upwards. When the root of the subclavian artery is dilated, its impression on the csophagus is not only large but there is also forward displacement of the œsophagus as in the cases described by Dahm, Kommerell, Ravelli, and others. Should the artery pass between the æesophagus and trachea it will produce an oblique indentation on the anterior esophageal wall as illustrated by Neuhauser (1946). No case of the vessel passing anterior to the trachea appears to have been diagnosed in life.

Differential Diagnosis. Narrowing of the lumen and displacement of the esophagus may be produced by tumours in the wall or lumen of the esophagus, mediastinal tumours, or enlarged mediastinal glands. These abnormalities can be excluded without much difficulty by careful fluoroscopy and adequate radiographs.

Vessels other than the subclavian artery may pass behind the œsophagus. A right-sided aorta with retrooesophageal arch and left descending aorta can be recognized by the presence of the aortic knuckle on the right. When the aortic arch and descending aorta are both on the right there may also be a retro-esophageal left subclavian artery, innominate artery, or ductus arteriosus. The indentation due to the left subclavian and innominate arteries will pass obliquely upwards and to the left. The defect produced by the ductus arteriosus lies below the level of the aortic arch. In pulmonary atresia large collateral vessels passing from the aorta to the lungs are a not uncommon cause of indentations on the œsophagus: these impressions will be seen usually below the level of the aortic arch.

The aberrant right subclavian artery produces fairly characteristic changes on the barium-filled œsophagus. The diagnosis can be confirmed by angiocardiography when the abnormality can be detected in the P.A. view, and is well shown in the L.A.O. view. Confirmation can also be obtained if necessary by passing a catheter up the right radial artery into the aorta as described by Raphael et al. (1952).

\section{SYMPTOMS}

The condition is usually asymptomatic and is diagnosed incidentally at fluoroscopic examination of the heart or gastro-intestinal tract.

Occasionally the artery indents the œsophagus sufficiently to cause dysphagia. This is commonest in infancy, and may be severe enough to warrant surgical division of the vessel. In many cases dysphagia consists of only mild hesitation in swallowing or regurgitation of feeds if these are not taken slowly. There may be delay in swallowing solids but not fluids or the reverse can occur. As the infant grows older there is a strong tendency for the spontaneous relief of symptoms.

Dysphagia may appear or recur in adults. Bayford described how a woman experienced dysphagia of gradually increasing intensity since childhood. She died at the age of 62 from 
inanition and at necropsy the artery was found passing between the œsophagus and trachea. Bayford gave the name Dysphagia Lusoria to difficulty in swallowing produced by an aberrant right subclavian artery.

Symptoms other than dysphagia are uncommon. In the case described by Kellock and Batten (1895) death occurred following lodgement of food in the upper osophagus. The child was cyanosed and dyspnœic: breathing ceased and death ensued in spite of tracheotomy. Post mortem, in addition to the anomalous right subclavian artery, the two carotid arteries were found to arise practically together. The right common carotid artery crossed in front of the trachea to reach the right side, and it seems that the respiratory difficulty resulted from the trachea being pushed forwards against it. Kreutzer et al. (1950) believed that pressure on the back of the trachea by the anomalous vessel, which passed anterior to the æsophagus, probably contributed to the dyspnœa present in their case of Fallot's tetralogy.

One case of fatal hæmorrhage due to perforation of the retro-œsophageal vessel by a fish bone was recorded by Kirby in 1818.

\section{CASE REPORTS}

Case 1. A boy, aged 4 years. Cyanosis and dyspnoea had been present since early infancy. A clinical diagnosis of Fallot's tetralogy was supported by angiocardiography and at operation. At routine fluoroscopy in the P.A. position, an indentation was detected on the œsophagus commencing at the summit of the aortic arch and passing upwards and to the right (Fig. 2A). The lateral and L.A.O. positions showed that the impression was retro-œsophageal. Angiocardiography demonstrated pulmonary infundibular stenosis and over riding aorta. In the L.A.O. view a film at two seconds showed clearly the course of the right subclavian artery (Fig. 2B).

An end-to-side subclavian-pulmonary anastomosis was performed by Mr. T. Holmes Sellors. No attempt was made to dissect out the right subclavian artery which was not required for the anastomosis.

Case 2. A girl, aged 4 years. Cyanosis was noted first when the infant began to crawl and there was a history of dyspnœa on exertion. Fallot's tetralogy was diagnosed.

On screening a faint oblique impression on the posterior œsophageal wall was noted lying just above the aortic arch in the P.A., lateral and oblique positions. It was broader than that in Case 1 (Fig. 3A). It was most obvious in the lateral and L.A.O. views. The angiocardiogram in the A.P. position demonstrated pulmonary infundibular and valvular stenosis. A film at $2 \frac{1}{4} \mathrm{sec}$. showed absence of the innominate artery. The proximal part of the right subclavian artery was seen clearly on the left side of and partly overlapping the right common carotid artery (Fig. 3B).

End-to-side anastomosis between the left subclavian and left pulmonary arteries was performed by Mr. Holmes Sellors. There was no necessity to dissect out the right subclavian artery.

Case 3. A girl, aged 3 years. Another case of Fallot's tetralogy with cyanosis present since birth and dyspncea on exertion.

At fluoroscopy an oblique indentation was visible on the posterior wall of the cesophagus lying a little above the aortic arch. At this level the œsophagus was very slightly displaced to the right (Fig. 4A). Angiocardiography in the A.P. position demonstrated a pulmonary infundibular stenosis and over-riding aorta. The film at two seconds showed an identical appearance to that in Case 2; absence of the right innominate artery and the proximal part of the right subclavian artery lying to the left of the right common carotid artery (Fig. 4B).

Case 4. A boy, aged 7 years. There was a history of moderate cyanosis at rest and severe cyanosis with dyspnœa on exertion. A diagnosis of Fallot's tetralogy was made.

At fluoroscopy in the P.A. position the œsophagus appeared normal but in the L.A.O. and lateral views an oblique indentation was seen on the posterior wall of the osophagus. The esophagus was displaced slightly forwards at this level (Fig. 5A). Angiocardiograms in the A.P. position showed a pulmonary stenosis and over-riding aorta. The first part of the right subclavian artery lay on the left side of the right common carotid artery. The appearances were similar to those shown in Fig. 3B and 4B. On the angiocardiogram film taken at two seconds in the R.A.O. position the right subclavian artery can be seen to arise at the junction of the arch and the descending aorta. From this point the vessel ascends before turning laterally over the first rib (Fig. 5B). 


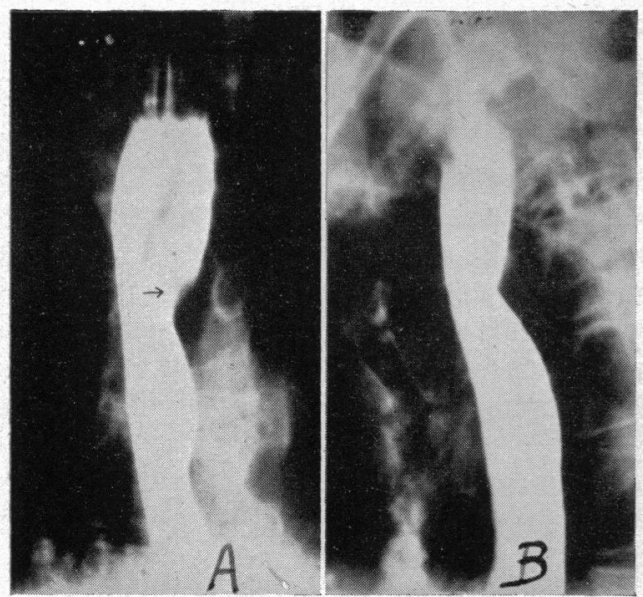

Fig. 6. Case 5, aged 46 years. (A) Antero-posterior position. (B) Lateral position. There is an indentation on the left wall of the esophagus $\frac{1}{2}$ inch above the aortic arch. From it a faint defect passes upwards and to the right. The indentation is shown clearly in the lateral view.

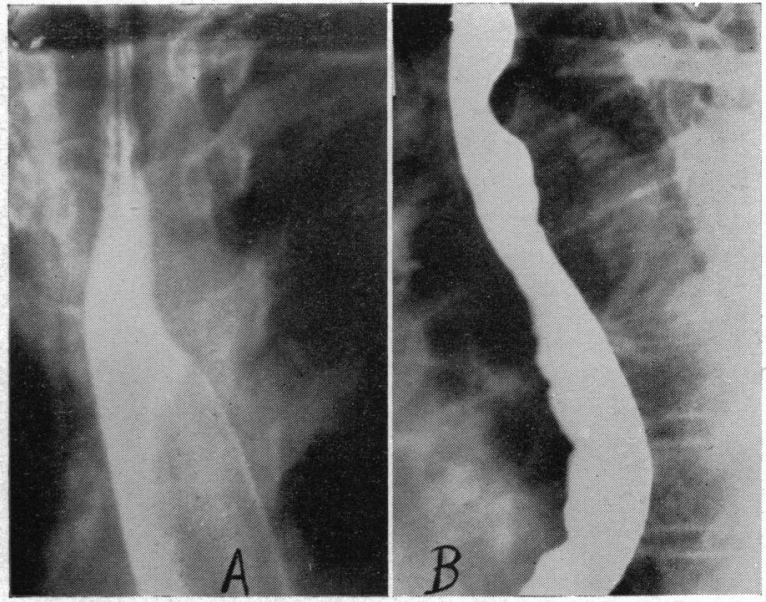

Fig. 7.-Case 7, aged 60. (A) A.P. position. The aberrant artery does not produce a visible defect on this film (B) Extreme L.A.O. position with patient supine, showing gastro-cesophageal reflux and a large semicircular defect on the posterior wall of the osophagus at the level of the aortic arch.
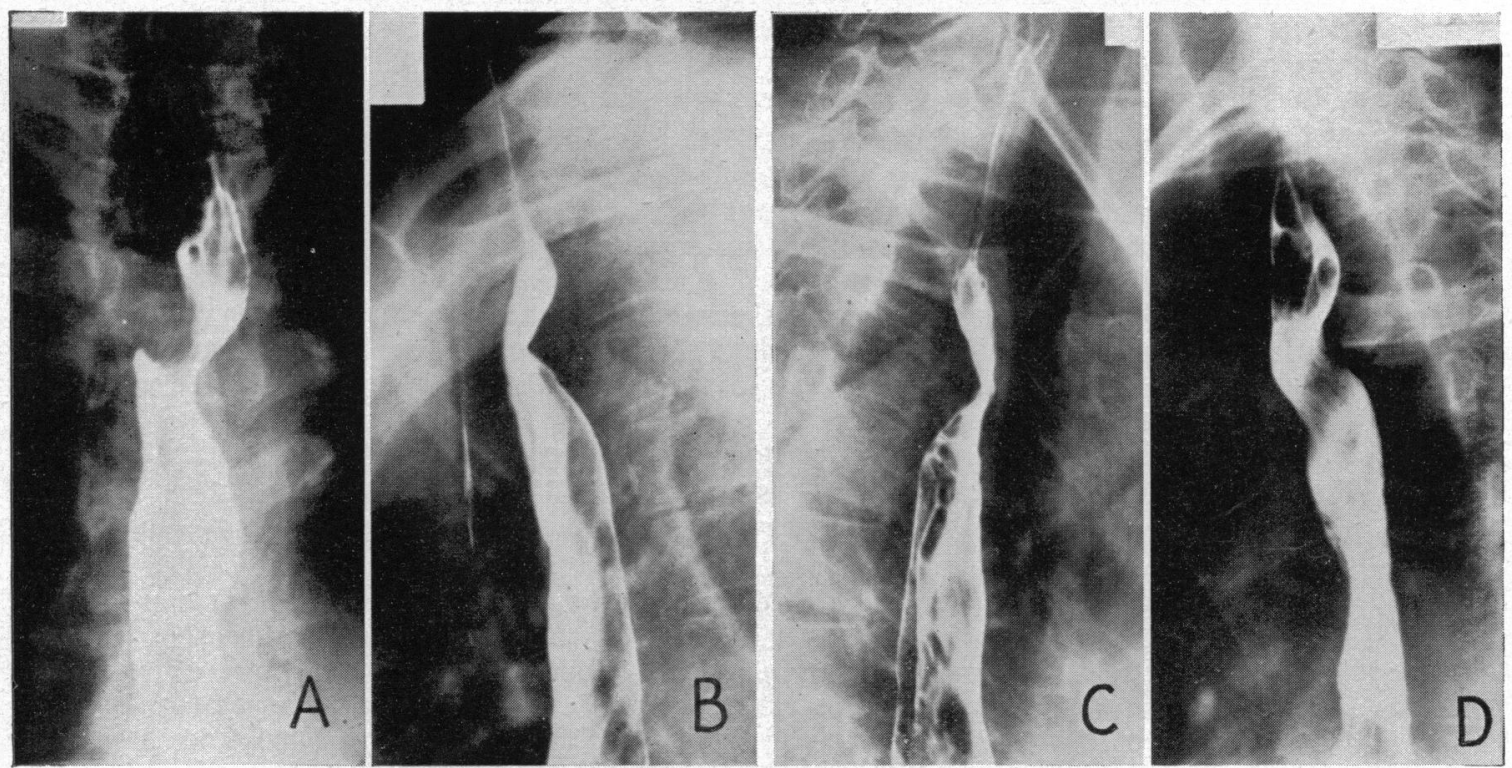

FIG. 8.-Case 6, aged 55 years. (A) There is a broad oblique impression running upwards and to the right from just below the summit of the aortic arch. It is most prominent on the right side of the cesophagus. (B) Lateral position. The cesophagus is slightly displaced forwards and there is a deep indentation on its posterior wall. (C) R.A.O. position and (D) L.A.O. position. The oblique impression is well shown in these views.

Case 5. A woman, aged 46 years. The patient complained of attacks of nausea and epigastric discomfort on and off for the past 14 years. A barium meal examination demonstrated a duodenal ulcer. A semicircular indentation on the left side of the csophagus $\frac{1}{2}$ inch above the summit of the aortic arch was also noted. A defect ran upwards and to the right of this indentation and gradually faded out towards the right side of the osophagus. In the L.A.O. and lateral positions an indentation was visible on the posterior œsophageal wall (Fig. 6). 
Case 6. A woman, aged 55 years. This patient was suffering from scleroderma, Reynaud's phenomenon, and rheumatoid arthritis. There was no history of dysphagia and no changes of scleroderma were detected in the gastro-intestinal tract at a barium-meal examination. However, a broad oblique impression was seen on the posterior œesophageal wall commencing just below the top of the aortic arch, and also a small indentation on the right side of the asophagus (Fig. 8). These impressions were unlike those due to a double aortic arch (with small posterior arch) and there was no indentation on the trachea in P.A. or lateral views.

Case 7. A woman, aged 60. There was a 20-year history of epigastric pain and more recently heartburn one hour after food. There was no dysphagia or vomiting. During a barium-meal examination free gastro-œsophageal reflux occurred when the patient lay on her right side, while in the Trendelenberg position. No hiatus hernia could be demonstrated. Lateral and oblique views showed a wide semicircular indentation on the posterior osophageal wall at the level of the summit of the aortic arch. The impression of the artery was very difficult to see in the P.A. view, being easily obscured by the barium bolus (Fig. 7).

\section{Discussion}

In the seven cases of aberrant right subclavian artery encountered during a period of 14 months, there was no history of dysphagia or other symptoms referable to the anomalous vessel. Fallot's tetralogy was diagnosed in four of them. During this time 5407 fluoroscopic examinations were carried out involving visualization of the osophagus by barium and 90 of these were in patients with clinical evidence of congenital heart disease. Hence the evidence of aberrant right subclavian artery in this radiological department is 0.13 per cent and amongst patients with congenital heart disease investigated at this hospital the incidence is 4.4 per cent. These figures do not reflect the true incidence of the anomalous vessel in congenital heart disease in general since they are influenced by the selected nature of congenital lesions coming for examination to a cardiac surgical centre. During the period under review, fluoroscopy was carried out in 44 cases of Fallot's tetralogy and in 33 the aortic arch lay on the left side. Thus the incidence of the 4 cases of aberrant right subclavian artery in this condition is 12 per cent. The overall incidence in this series is much less than the incidence of 0.6 per cent found by Holzapfel (1899) in post-mortem material. In adults the anomalous vessel may cause little or no œsophageal deformity in the P.A. and R.A.O. positions and possibly a number of cases have not been detected at routine fluoroscopy. In children with congenital heart disease the barium filled œsophagus is scrutinized with great care, especially in the region of the aortic arch, and even minor indentations are less likely to be overlooked.

Brean and Neuhauser (1947) were the first to draw attention to the combination of this anomalous vessel and congenital heart disease. The incidence of 12 per cent in Fallot's tetralogy found in our series suggests that the aberrant artery is more commonly associated with this condition than with a normal heart.

The recognition of a retro-œsophageal vessel may be of more than academic interest. Dysphagia and stridor are well-known symptoms of double aortic arch and may even cause death in infancy or childhood. Severe dysphagia is much less common with an aberrant right subclavian artery but in these cases complete relief of symptoms can be obtained by surgical division of the first part of the artery as described by Gross and Ware (1946). The arm receives an adequate blood supply through collateral vessels communicating with the second and third parts of the subclavian artery.

The presence of a retro-œsophageal vessel can be recognized with ease radiologically. Awareness of its existence is of value to the surgeon in planning operation in cases of Fallot's tetralogy. Accurate identification of the vessels arising from the aortic arch is essential before performing an anastomosis between the subclavian and pulmonary arteries. The origin of the anomalous vessel on the medial side of the aortic arch may be difficult to see and it can be overlooked. Bahnson and Blalock (1950) record that in three cases operated on early in their series the aberrant artery was not recognized and the carotid artery was used with its greater operative risk. Blalock (1948) states the retro-œsophageal right subclavian artery may be used to provide a satisfactory anastomosis with the right pulmonary artery: in most patients he performed the anastomosis without disturbing 
the position of the artery, but in some the artery was divided distally and then brought round to the left and anterior to the œsophagus before anastomosing it with the right pulmonary artery.

The anomalous vessel may be associated with types of congenital cardiovascular disease other than pulmonary stenosis. A patent ductus was present in three of the cases described by Brean and Neuhauser (1947). East (1932) reported its occurrence in a post-mortem specimen in combination with coarctation of the aorta.

\section{SUMMARY}

The reported cases of an anomalous right subclavian artery are reviewed briefly.

Seven examples of this condition are reported, four of which were associated with Fallot's tetralogy. The barium swallow and angiocardiographic appearances in some of the cases are described.

Attention is drawn to the value of radiological recognition of this anomaly in patients with dysphagia and in cases where it is associated with Fallot's tetralogy.

I am much indebted to Dr. Evan Bedford and to Mr. T. Holmes Sellors for permission to publish details of the cases of Fallot's tetralogy and to Professor A. Kekwick, Mr. D. Patey and Mr. R. Vaughan Hudson for allowing me to give the clinical findings of their patients. I wish to thank Sir Harold Graham Hodgson for his interest and support. I am most grateful to Mr. Turney of the Photographic Department of the Middlesex Hospital for the photographic reproductions.

\section{REFERENCES}

Apley, J. (1949). Proc. roy. Soc. Med., 42, 918

Bahnson, H. T., and Blalock, A. (1950). Ann. Surg., 131, 356.

Bayford, D. (1794). Mem. Med. Soc. London, $2,275$.

Blalock, A. (1948). Surg. Gynec. Obstet., 87, 385.

Brean, H. P., and Neuhauser, E. D. B. (1947). Amer. J. Roentgenol., 58, 708.

Cairney, J. (1925). J. Anat., Lond., 59, 265.

Congdon, E. D. (1922). Transformations of Aortic Arch System, No. 68 Carnegie Inst. Washington. Pub., $277,47$.

Copleman, B. (1945). Amer. J. Roentgenol., 54, 270.

Dahm, M. (1940). Fortschr. Rontgenstr., 62, 108.

East, T. (1932). Proc. roy. Soc. Med., 25, 798.

Edwards, J. E. (1948). Proc. Mayo Clin., 23, 108.

Felson, B., Cohen, S., Courter, S. R., and McGuire, J. (1950). Radiology, 54, 340.

Gross, R. E., and Neuhauser, E. D. B. (1951). Pediatrics, 7, 69.

- , and Ware, P. F. (1946). Surg. Gynec Obstet., 83, 435.

Gunsel, E. (1940). Rontgenpraxis, 12, 346.

Holzapfel, G. (1899). Anat. Hefte. Beitrage, 12, 373.

Hunauld, - Quoted by Holzapfel (1899).

Kellock, T. H., and Batten, F. E. (1895), Lancet, 1, 1579.

Kirby, J. (1818). Dublin Hosp. Rep., $2,224$.

Kommerell, B. (1936). Fortschr. Rontgenstr., 54/6, 590.

Kreutzer, R. O., Caprile, J. A., and Wessels, F. M. (1950). Brit. Heart J., 12, 293.

Neuhauser, E. B. D. (1946). Amer. J. Roentgenol., 56, 1.

Raphael, R. L., Schnabel, T. G., and Leopold, S. S. (1952). Radiology, 58, 89.

Ravelli, A. (1950). Fortsch Rontgenstr., 73/3, 285.

Stauffer, H. M., and Pote, H. H. (1946). Amer. J. Roentgenol., 56, 13.

Zdansky, - (1939). Rontgendiagnostik des Hersens und der Grossen. Gefass. Springer, Vienna, p. 365. 